\title{
Application of Bimodal Histogram Method to Oil Spill Detection from a Satellite Synthetic Aperture Radar Image
}

\author{
Tae-Sung Kim*, Kyung-Ae Park**; Min-Sun Lee*, Jae-Jin Park*, \\ Sungwook Hong ${ }^{\star \star *}$, Kum-Lan Kim ${ }^{\star \star *}$ and Eunmi Chang ${ }^{\star \star * *}$ \\ *Department of Science Education, Seoul National University \\ **Department of Earth Science Education / Research Institute of Oceanography, Seoul National University \\ ***Satellite Analysis Division, National Meteorological Satellite Center, Korea Meteorological Administration

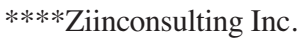

\begin{abstract}
As one of segmentation techniques for Synthetic Aperture Radar (SAR) image with oil spill, we applied a bimodal histogram method to discriminate oil pixels from non-oil pixels. The threshold of each moving window was objectively determined using the two peaks in the histogram distribution of backscattering coefficients from ENVISAT ASAR image. To reduce the effect of wind speed on oil spill detection, we selected ASAR image which satisfied a limit of wind speeds for successful detection. Overall, a commonly used adaptive threshold method has been applied with a subjectively-determined single threshold. In contrast, the bimodal histogram method utilized herein produces a variety of thresholds objectively for each moving window by considering the characteristics of statistical distribution of backscattering coefficients. Comparison between the two methods revealed that the bimodal histogram method exhibited no significant difference in terms of performance when compared to the adaptive threshold method, except for around the edges of dark oil spots. Thus, we anticipate that the objective method based on the bimodality of oil slicks may also be applicable to the detection of oil spills from other SAR imagery.
\end{abstract}

Key Words : Oil Spill, SAR, Adaptive Threshold, Bimodal Histogram

\section{Introduction}

Synthetic Aperture Radar (SAR) sensor is one of the most important active sensors, capable of visualizing the surface of the earth. It sends a chirp pulse of microwaves at $\mathrm{C}-, \mathrm{K}-$, or L-bands to the sea surface and receives a backscattering cross section transmitted back to the sensor in space. The backscattering coefficient, or sigma naught, can be used to retrieve a variety of oceanic variables. Overall, these SAR sensor satellite systems can measure $50-500 \mathrm{~km}^{2}$ regions with spatial resolutions of about 10-100 m, and are frequently

Received December 16, 2013; Accepted December 19, 2013.

$\dagger$ Corresponding Author: Kyung-Ae Park (kapark@snu.ac.kr)

This is an Open-Access article distributed under the terms of the Creative Commons Attribution Non-Commercial License (http://creativecommons. org/licenses/by-nc/3.0) which permits unrestricted non-commercial use, distribution, and reproduction in any medium, provided the original work is properly cited 
utilized to monitor oceanic phenomena.

Ever since the primitive SAR system of Seasat launched in 1979, SAR sensors have long been used to observe the earth accurately and precisely through multi-polarization, multi-wave length, and multi-mode observations. SAR satellite data has been utilized for a wide range of marine meteorological fields, such as monitoring of ocean waves (Alpers et al., 1981; Kasischke et al., 1988; Hasselmann and Haselmann, 1991; Engen and Johnsen, 1995; Collard et al., 2005), ocean currents (Shemer et al., 1993; Graber et al., 1996; Kang and Lee, 2007), sea surface winds (Gerling, 1986; Monaldo et al., 2001; Xu et al., 2010; Kim and Park, 2011; Kim et al., 2012), and internal waves (Rodenas and Garello, 1997; Liu and Hsu, 2004), and ship detection (Ouchi et al., 2004; Liao et al., 2008), submarine detection (Liu et al., 1996), intertidal zone changes (Mason et al., 1995; Van der Wal et al., 2005), and coastal soil information (Bell et al., 2001). One other application is oil spill detection with devastating hazards along coastal regions.

One of the important preconditions for oil spill detection is an appropriate wind speed at the time, which is sufficient to generate Bragg waves. SARs measure the backscattered radar power interacted with Bragg waves in centimeter-long wavelengths at a moderate incidence angle between 20 and 70 degrees (Valenzuela, 1978). The existence of surface films significantly dampens short gravity-capillary waves (Lucassen, 1982; Huehnerfuss et al., 1983; Huehnerfuss et al., 1987; Alpers and Huehnerfuss, 1989), hence the regions covered with oil can be detected by analyzing their backscattering contrast. At low wind speeds of less than 2-3 m/s, backscattering from the sea surface as a whole tends to be very weak, so that no significant signature of oil slicks appears (Bern et al., 1992; PerezMarrodan, 1998). Likewise, at high wind speeds of over $10-14 \mathrm{~m} / \mathrm{s}$, the damping effect disappears in the background noise of wind-generated waves (Demin et al., 1985; Bern et al., 1992; Litovchenko et al., 1999).
Therefore, oil spill detection using SAR data is only applicable in a wind range of $2-14 \mathrm{~m} / \mathrm{s}$. Thus, we only utilized SAR imagery which satisfies this condition.

A variety of research for oil spill detection using SAR images has been attempted, which is important for coastal monitoring and understanding of physical oceanographic process. In most of cases, oil spills have been studied using single polarization, such as $\mathrm{HH}$ or VV, from European Remote Sensing 1/2 (ERS-1/2), and Environmental Satellite (ENVISAT), RADARSAT1. Very recently, a new method has also been developed to utilize multi-polarization $(\mathrm{HH} / \mathrm{HV} /$ $\mathrm{VH} / \mathrm{VV}$ ) SAR images in the detection of oil spills at the sea surface (Zhang et al., 2011; Migliaccio et al., 2011). However, the full polarization observation of SAR has been difficult to readily obtain due to its infrequent measurement schedule and its limitations in regards to diverse applications.

In the seas around Korea, there have been only a few studies to detect oil spills from SAR images. In addition, a relatively simple method, adaptive threshold method, has been utilized (Yang et al., 2009; Park et al., 2010; Kim et al., 2010). The adaptive threshold method has the advantage of being able to reduce computation time, but it also has a disadvantage in terms of the difficulty of setting the threshold objectively. Thus, a more robust method capable of determining the threshold objectively and automatically for operational purposes is necessary. Therefore, in this study, we introduce the bimodal histogram method for oil spill detection from SAR images with a single polarization, and then compare this method with the adaptive threshold method.

The objectives of this study are (1) to apply the adaptive threshold method algorithm to detect oil spills from an ENVISAT SAR image, (2) to develop the bimodal histogram method based on the Gaussian fitting method, and (3) to compare the two methods and present some differences. 


\section{Data}

Since most SARs observe the sea surface with an insufficient temporal resolution, it is hard to obtain SAR imagery which includes the significant features of oil spills at the seas around Korea. Therefore, we searched European Space Agency's (ESA) quick-look images of the world's oceans and seas and collected SAR images which contained oil-covered areas. Among them, we selected the SAR image from ENVISAT Advanced Synthetic Aperture Radar (ASAR) off the coast of Libya in the Mediterranean Sea which showed obvious dark patches originated from natural oil seeps (Fig. 1). The SAR data was utilized to apply the oil spill detection methods and investigate the characteristics of each detection method. Details of the ENVISAT ASAR image used in this study were summarized in Table 1.

The ENVISAT ASAR image was taken at $9 \mathrm{~h} 7 \mathrm{~m}$ (UTC) on 17 September, 2006. The center of the study area is located at $14.66^{\circ} \mathrm{E}, 32.82^{\circ} \mathrm{N}$. The ASAR data was obtained at C-band $(5.331 \mathrm{GHz})$ with $\mathrm{HH}$ polarization. The coverage of the ASAR image covers approximately $82 \mathrm{~km}$ in the range direction and $46 \mathrm{~km}$ in the azimuthal direction. The looking angle of the ASAR image ranges from $25.7^{\circ}$ to $31.2^{\circ}$ from nadir and the spatial resolution is $12.5 \mathrm{~m}$.

In order to investigate whether or not the SAR image can be used for the detection of oil spills at the local region, we used wind speed measurements from Quick
Scatterometer (QuikSCAT) at similar time to the observation time of SAR. The wind speed was $7.2 \mathrm{~m} / \mathrm{s}$ for the study area in Fig. 1b, which satisfies the range limit for oil spill detection using SAR data. Overall, the thresholds of wind speed for detection were from 2-3 to $10-14 \mathrm{~m} / \mathrm{s}$ (Demin et al., 1985; Bern et al., 1992; Perez-Marrodan, 1998; Litovchenko et al., 1999).

\section{Method}

\section{1) Estimation of backscattering coefficient}

Prior to applying oil spill detection algorithms, ENVISAT ASAR data was processed to extract the backscattering coefficients $\left(\sigma_{0}\right)$. For ENVISAT ASAR data, a intensity of detected radar brightness was retrieved after elevation antenna patterns and rangespreading loss corrections without any incidence angle correction. Thus, the Normalized Radar Cross Section (NRCS) can be derived from detected pixel values by correcting the effect of the incidence angle. The relationship between the value of power at an image pixel, $I$, and NRCS is as follows:

$$
\sigma_{0}=\frac{<P>}{K} \sin (\alpha)
$$

where $<>$ indicates the spatial average of the pixel values around the target, $\alpha$ is the incidence angle, and $K$ is an absolute calibration constant. The derived NRCS values were converted to units of $\mathrm{dB}$.

Fig. $1 \mathrm{~b}$ shows the distribution of the derived NRCS

Table 1. Information of SAR image used in this study

\begin{tabular}{c|c}
\hline \hline Parameter & ENVISAT SAR \\
\hline Frequency $(\mathrm{GHz})$ & $5.331(\mathrm{C}-$ band $)$ \\
\hline Polarization state & Single-polarization $(\mathrm{HH})$ \\
\hline Swath width $(\mathrm{km})$ & 82.83 \\
\hline Azimuthal range $(\mathrm{km})$ & 46.07 \\
\hline Resolution $(\mathrm{m})$ & $12.5 \times 12.5$ \\
\hline Look angle $(\mathrm{deg})$ & $25.74^{\circ}-31.22^{\circ}$ \\
\hline Acquired time & $09 \mathrm{~h} 07 \mathrm{~m} 18 \mathrm{~s}(\mathrm{UTC})$ on 17 September, 2006, \\
\hline Central location & $14.66^{\circ} \mathrm{E}, 32.82^{\circ} \mathrm{N}$ \\
\hline \hline
\end{tabular}



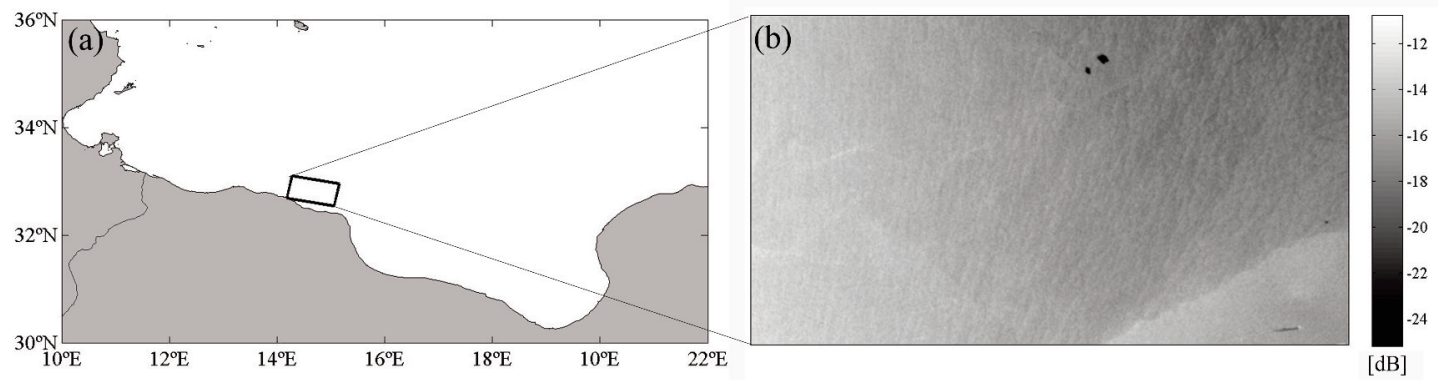

Fig. 1. (a) Location of study area (marked in a small box) and (b) distribution of backscattering cross section from ENVISAT ASAR in the ocean near Libya on 17 September 2006.

values in the study area, where the bright pixels (>-16

$\mathrm{dB})$ are of larger values than dark pixels $(<-20 \mathrm{~dB})$. The values of $\sigma_{0}$ ranged from $-25.2 \mathrm{~dB}$ to $-10.7 \mathrm{~dB}$ and the mean of the values for the entire area amounted to - 15.7 $\mathrm{dB}$. The dark patches on the upper middle part of the image have much lower values (dark) than those of the background data (bright). These features were assumed to be associated with the damping of Bragg resonant waves due to the presence of oil slicks.

\section{2) Adaptive threshold method}

In general, pixels which demonstrate no significant difference in terms of some environmental condition (e.g., wind speed, sea surface temperature) tend to show similar NRCS values, whereas pixels in regions covered with oil tend to contain much lower NRCS
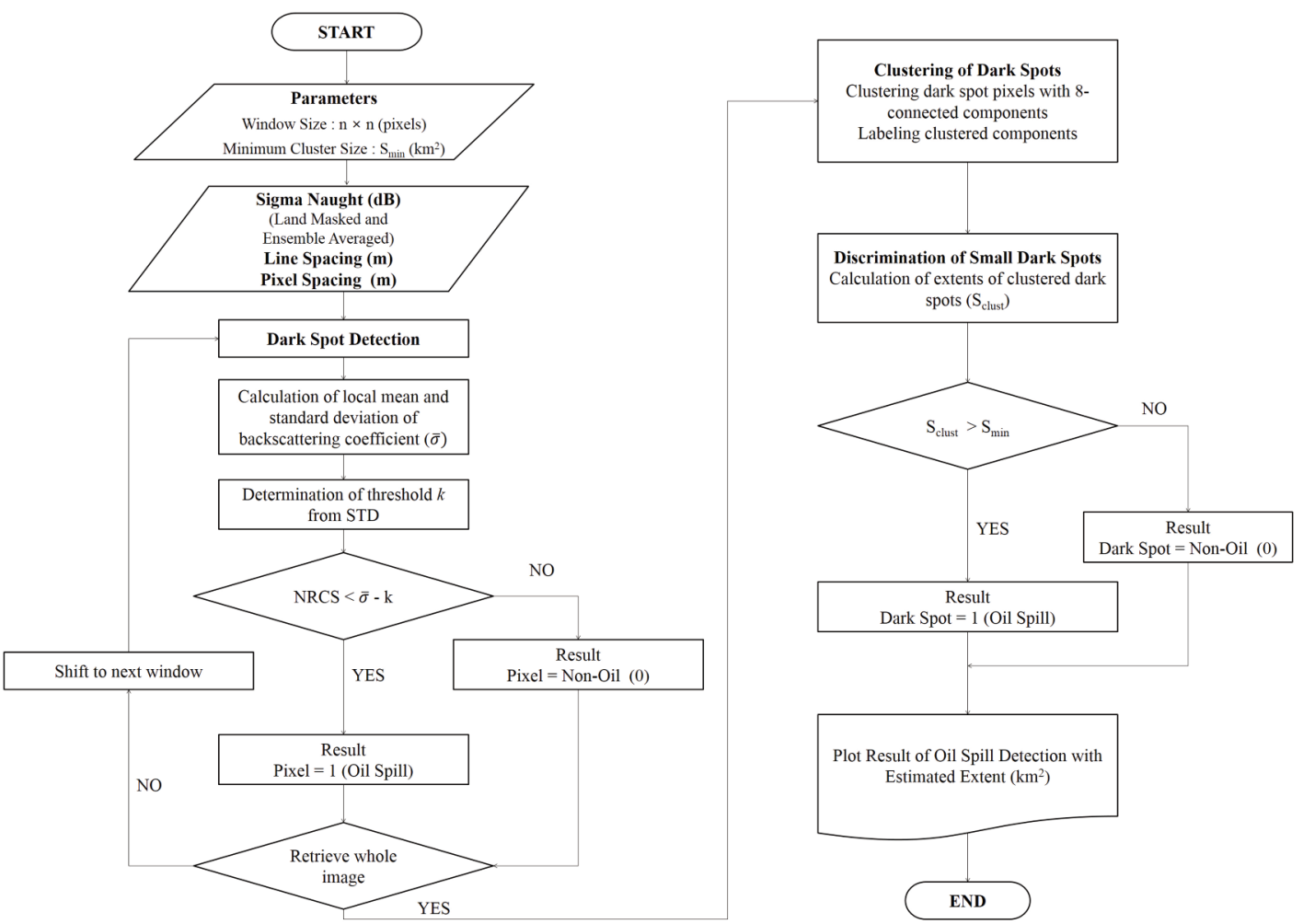

Fig. 2. Flow chart of adaptive threshold method for oil spill detection, clustering the detected oil pixels, and the calculation of areas filled with oil. 
values than those of the surrounding background due to the damping effect. This suggests that oil slicks are characterized by low backscattering under a certain NRCS level. If we give a proper threshold, the dark spots can be separated from the surrounding non-oil pixels at the sea surface.

The adaptive threshold method is one of the most widely used methods for oil spill detection from SAR images among those techniques which employ a threshold. Such techniques determine a threshold within each window of size $N \times N$ with a mean and standard deviation from each moving window (Vachon et al., 1998; Solberg et al., 1999 ). Based on these simple thresholds, pixels in a window whose NRCS values are lower than the thresholds are detected as oil spills.

Fig. 2 shows the schematic flow chart of oil spill detection for SAR data by the adaptive threshold method. Before applying the method, the input parameters including the window size, minimum cluster size in extent $\left(\mathrm{km}^{2}\right)$, and threshold $k(\mathrm{~dB})$ were given. To reduce speckle noises, NRCSs were averaged in $5 \times 5$ window after land masking procedure. Using the NRCS, the adaptive threshold in a moving window was estimated and then low backscattering pixels regarded as dark spots were separated according to the threshold. To better separate the spill from its surroundings and estimate the extent of the oil-covered area, the detected dark spots were clustered using connectivity in eight neighbourhood directions. Based on the estimated extents, clusters of dark spots which were smaller than the minimum cluster size were assumed to be look-alikes and discriminated.

\section{3) Bimodal histogram method}

The bimodal histogram method separates oil spills from the sea surface based on the distribution of NRCS in a window (Skøelv and Wahl, 1993). As shown on Figs. 3a and 3b, generally a sea surface without oil has a form of histogram with unimodal distribution. On the
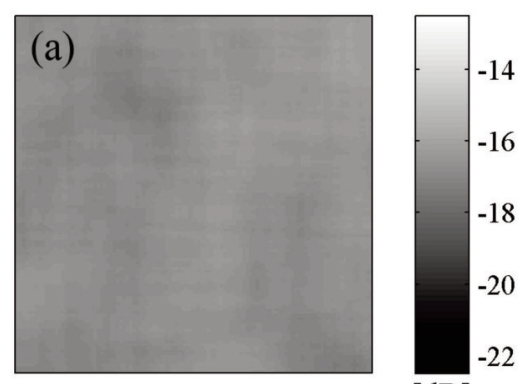

$[\mathrm{dB}]$
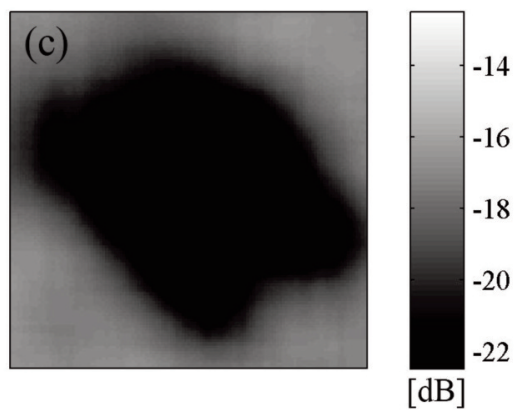
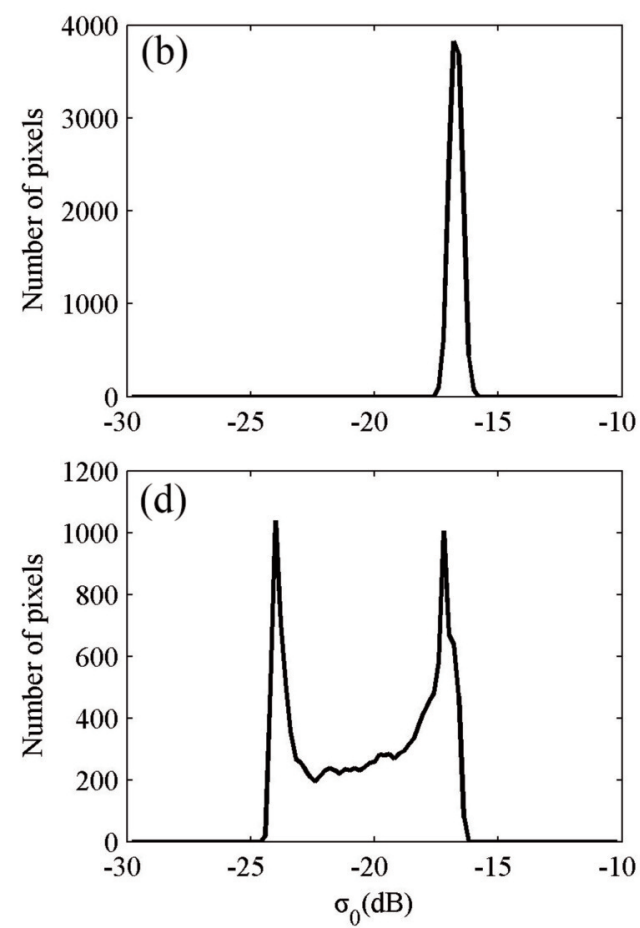

Fig. 3. (a) Spatial distribution of backscattering coefficient at an area without any oil spill and (b) its histogram, (c) backscattering coefficient within a window for oil spill detection based on the bimodal histogram method and (d) its histogram. 

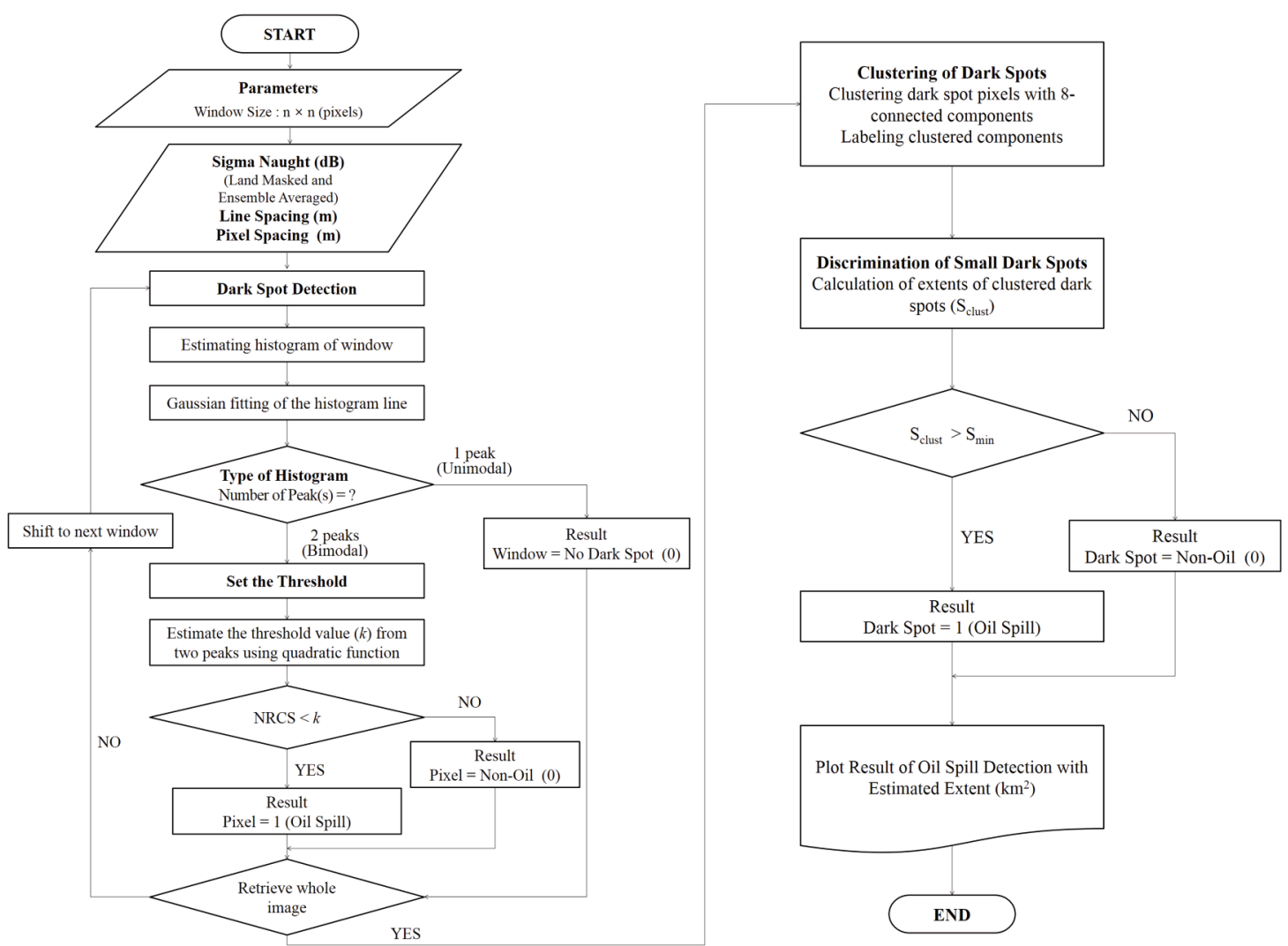

Fig. 4. Flow chart of the bimodal histogram method for oil spill detection, clustering the detected oil pixels, and the calculation of areas filled with oil.

contrary, a sea surface with oil slicks shows a bimodal distribution which has two distinct peaks, since oil slicks typically have much lower NRCS values than the surrounding background (Figs. 3c and 3d). Thus, oil spills in SAR images can be identified by analyzing the form of histogram produced.

Fig. 4 shows the schematic flow chart of oil spill detection for SAR data using the bimodal histogram method. In general much of the procedure is similar to that of the adaptive threshold method, with the exception of histogram analysis and threshold determination. While the threshold of the former method was simply given based on the mean and standard deviation, that of the latter method was deduced from the characteristics of statistical distribution.
Before analyzing a form of distribution and calculating a threshold, a histogram in a moving window is fitted to multimodal Gaussian distribution functions as follows;

$$
f_{N}(x)=\sum_{n=1}^{N} a_{n} e^{-\frac{\left(x-b_{n}\right)^{2}}{c_{n}^{n}}}
$$

where $N$ is the total number of modes, which indicates unimodal (1-peak) and bimodal (2-peak) Gaussian distributions when $N=1$ and $N=2$, respectively, and $a_{n}, b_{n}$, and $c_{n}$ are coefficients for $n$th mode Gaussian fitted functions. By comparing calculated $f_{1-3}$ and its coefficient of determination $R^{2}$, it was determined which mode is the best fit to a form of histogram in a moving window. 


\section{Results}

\section{1) Adaptive threshold method}

Fig. 5 presented the distribution of NRCS at the study area and the derived results of oil spill detection based on the adaptive threshold method. Oil slicks with rounded shapes appeared around the upper middle part of the image (enlarged images on Figs. 7a and 7b). In

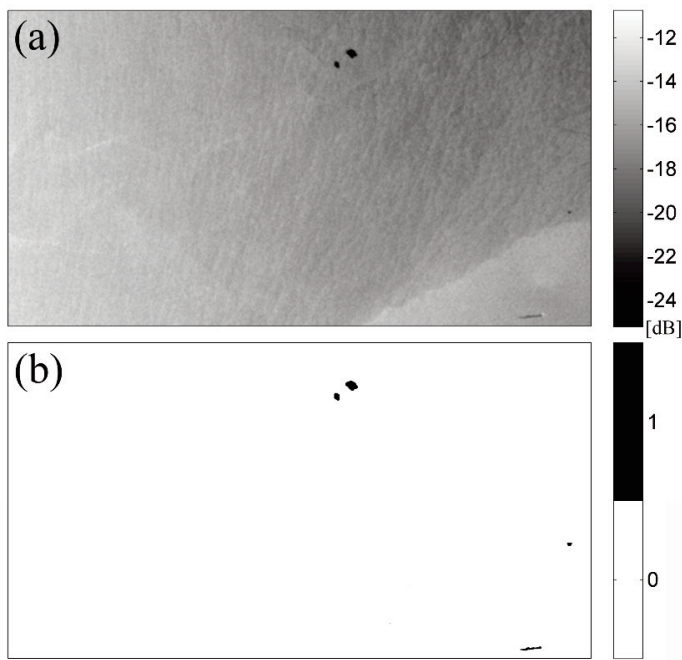

Fig. 5. (a) Spatial distribution of ENVISAT backscattering coefficient (sigma naught) with oil spill and (b) the analysis results of oil spill pixels using the adaptive threshold method, where 1 is oil and 0 is a non-oil pixel.

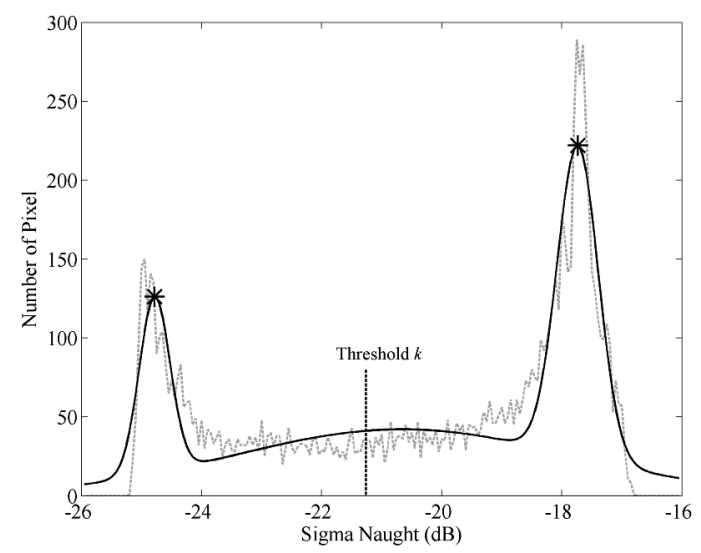

Fig. 6. An example of the bimodal histogram method by fitting Gaussian distribution functions with two peaks, marked as stars on the solid fitted line, onto a histogram of backscattering coefficients denoted with a dotted gray line. addition, linear or dotted dark spots assumed to be artificial structures or noises (look-alikes) were also detected to some extent. These small dark spots can be discriminated by setting minimum cluster size. In this study, we set the minimum cluster size to a value of 0.1 $\mathrm{km}^{2}$ in order to remove these look-alikes. After clustering and discrimination, the extent of the dark spots was calculated. The extent of the dark spots detected by the adaptive threshold method was estimated to be $1.87 \mathrm{~km}^{2}$.

\section{2) Bimodal histogram method}

To detect oil spills the bimodal histogram method was also applied. Fig. 6 demonstrates an example of a threshold determined using the bimodal threshold method. A histogram of a window shows a typical form of bimodal distribution. The values of for Gaussian fitted functions were $0.01\left(f_{1}\right), 0.51\left(f_{2}\right)$, and $0.87\left(f_{3}\right)$, respectively. We fitted the histogram to the Gaussian function and found peaks of bimodal distribution.

A threshold in each window was set to the middle point of two peaks. While thresholds determined by the adaptive threshold method vary with a moving window (i.e., a value of threshold decreases as more pixels of oil are included in a window, and vice versa), locations of the peaks in a bimodal histogram are rarely affected by the size of the window. This method is not a subjective method, but rather an objective method that does not require any a prior knowledge of backscattering coefficients as a threshold. It can be automatically determined in a series of algorithms. Thus, the bimodal histogram method is seems to yield a more consistent result. It is known as an elaborate and efficient method for detecting oil spills which are not too thin (Brekke and Solberg, 2005).

For the ENVISAT ASAR image in Fig. 7a, we applied the bimodal histogram method described herein and obtained the analysis result of oil spill pixels in Fig. 7c. Number 1 corresponds to oil pixels. The two dark spots seem to be relatively well detected in comparison 
to the original backscattering coefficients (Fig. 7a). The result is similar to that obtained with the adaptive threshold method.

\section{3) Comparison of detection methods}

In order to illustrate the differences between the two detection methods, we compared the analysis results of the bimodal histogram method with those of the adaptive threshold method. First of all, we subtracted the flag numbers of Fig. 7c from those of Fig. 7b. Differences ranged from -1 to 1 as shown in Fig. 7d. Dominant differences appeared at the boundaries of the detected dark spots.

The circular pattern in Fig. 7d exhibited both positive and negative values for both small and large oil spots. Detailed examination of the oil flags showed that pixels with a difference of 1 were a little larger than those of -1 . The total area of dark spots detected by the bimodal histogram method was estimated to be $1.74 \mathrm{~km}^{2}$, which were slightly smaller and more rounded than those detected by the adaptive threshold method.

The distribution of differences between the two methods indicated that the bimodal histogram method
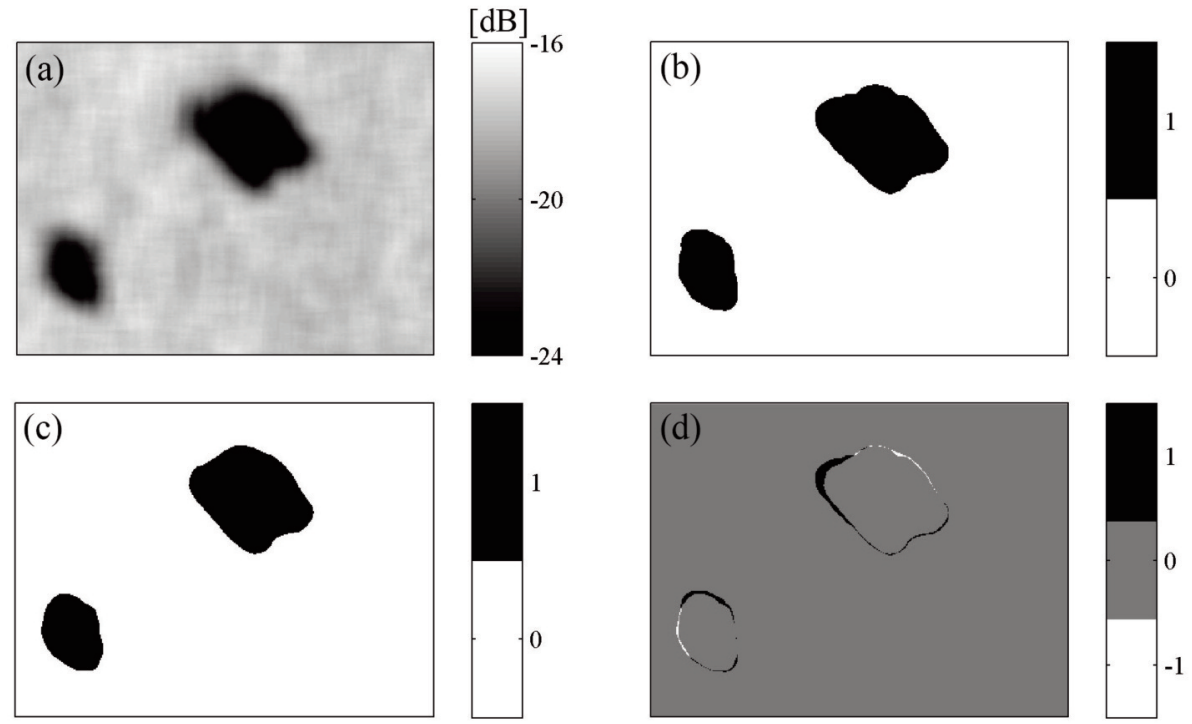

Fig. 7. (a) Spatial distribution of ENVISAT ASAR backscattering coefficient (sigma naught) with oil spill and the analysis results of oil spill pixels using (b) the adaptive threshold method and (c) the bimodal histogram method, where 1 is oil and 0 is a non-oil pixel, and (d) their differences, (b)-(c). 
method to an ENVISAT ASAR image with oil spills which satisfied the limit of wind speed, and then compared the results with those from the previous method. Until now, most of oil spill detection from SAR data have depended solely upon the adaptive threshold method. Since the method is fairly subjective, this study attempts to apply a more objective threshold method based on the statistical characteristics of bimodality of histogram. When compared with the results from the adaptive threshold method, the bimodal histogram method shows no significant difference, with the exception of negligibly small errors at the boundaries of dark spots. This implies that a method utilizing an objective threshold, such as the bimodal histogram method used in this study, has an applicability for oil spill detection in other SAR imagery in other oceanic regions.

In addition to the two methods introduced here, other methods have been developed for oil detection in SAR images, such as the neural network method, decomposition analysis, or the conformity coefficient method. However, these methods need more in-situ measurements of oil and reference data, or fullpolarized SAR data to yield the results. The method used in this study does not require any prior knowledge of backscattering coeffecients as a threshold. In addition, it does not require any polarization, such as $\mathrm{HH}, \mathrm{VV}$, or HV. Thus, this study is expected to make a contribution to the monitoring and detection of oil spills in the ocean, in an automatic and objective manner suitable to the use of SAR images.

\section{Acknowledgements}

This study was supported by the National Meteorological Satellite Center (Project No. 153-31003137-301-210-13). This study was also supported in part by EAST-I project of the Ministry of Oceans and Fisheries, Korea. We are very grateful to the unknown reviewers for their helpful comments.

\section{References}

Alpers, W. and H. Huhnerfuss, 1989. The damping of ocean waves by surface films: A new look at an old problem, Journal of Geophysical Research, 94: 6251-6265.

Alpers, W.R., D.B. Ross, and C.L. Rufenach, 1981. On the detectability of ocean surface waves by real and synthetic aperture radar, Journal of Geophysical Research, 86(C7): 6481-6498.

Bell, D., C. Menges, W. Ahmad, and J. Van Zyl, 2001. The application of dielectric retrieval algorithms for mapping soil salinity in a tropical coastal environment using airborne polarimetric SAR, Remote Sensing of Environment, 75(3): 375384.

Bern, T.-I., T. Wahl, T. Andersson, and R. Olsen, 1992. Oil spill detection using satellite based SAR: Experience from a field experiment, Proc. of 1st ERS-1 Symposium, Cannes, France, Nov. 46, pp. 829-834.

Brekke, C. and A. H. Solberg, 2005. Oil spill detection by satellite remote sensing, Remote Sensing of Environment, 95(1): 1-13.

Collard, F., F. Ardhuin, and B. Chapron, 2005. Extraction of coastal ocean wave fields from SAR images, IEEE Journal of Oceanic Engineering, 30(3): 526-533.

Demin, B.T., S.A. Ermakov, N.Y. Pelinovsky, T.G. Talipova, and A.I. Sheremet'yeva, 1985. Study of the elastic properties of sea surface-active films, Atmospheric Oceanic Physics, 21: 312316.

Engen, G. and H. Johnsen, 1995. SAR-ocean wave inversion using image cross spectra, IEEE Transactions on Geoscience and Remote Sensing, 33(4): 1047-1056. 
Gerling, T., 1986. Structure of the surface wind field from the Seasat SAR, Journal of Geophysical Research, 91(C2): 2308-2320.

Graber, H.C., D.R. Thompson, and R.E. Carande, 1996. Ocean surface features and currents measured with synthetic aperture radar interferometry and HF radar, Journal of Geophysical Research, 101(C11): 25813-25832.

Hasselmann, K. and S. Hasselmann, 1991. On the nonlinear mapping of an ocean wave spectrum into a synthetic aperture radar image spectrum and its inversion, Journal of Geophysical Research, 96(C6): 10713-10729.

Huehnerfuss, H., W. Walter, P.A. Lange, and W. Alpers, 1987. Attenuation of wind waves by monomolecular sea slicks and the Marangoni effect, Journal of Geophysical Research, 92: 3961-3963.

Huehnerfuss, H., W. Alpers, W.D. Garrett, P.A. Lange, and S. Stolte, 1983. Attenuation of capillary and gravity waves at sea by monomolecular organic surface films, Journal of Geophysical Research, 88: 9809-9816.

Kasischke, E.S., D.R. Lyzenga, R.A. Shuchman, and C.C. Wackerman, 1988. Contrast ratios of internal waves in synthetic aperture radar imagery: A comparison of SAR internal wave signature experiment observations with theory, Journal of Geophysical Research, 93(C10): 12355-12369.

Kang, M.K. and H. Lee, 2007. Estimation of ocean current velocity near Incheon using Radarsat-1 SAR and HF-radar data, Korean Journal of Remote Sensing, 23(5): 421-430.

Kim, D.-J., W.M. Moon, and Y.-S. Kim, 2010. Application of TerraSAR-X data for emergent oil-spill monitoring, IEEE Transactions on Geoscience and Remote Sensing, 48(2): 852863.

Kim, T.S. and K.A. Park, 2011. Estimation of polarization ratio for sea surface wind retrieval from SIR-C SAR Data, Korean Journal of Remote Sensing, 27(6): 729-740.

Kim, T.S., K.A. Park, W.M. Choi, S. Hong, B.C. Choi, I. Shin, and K.R. Kim, 2012. L-band SARderived sea surface wind retrieval off the east coast of Korea and error characteristics, Korean Journal of Remote Sensing, 28(5): 477-487.

Liao, M., C. Wang, Y. Wang, and L. Jiang, 2008. Using SAR images to detect ships from sea clutter, IEEE Geoscience and Remote Sensing Letters, 5(2): 194-198.

Litovchenko, K., A. Ivanov, and S. Ermakov, 1999. Detection of oil slicks parameters from ALMAZ-1 and ERS-1 SAR imagery, Proc. of 1999 IEEE International Geoscience and Remote Sensing Symposium(IGARSS'99), Hamburg, Germany, Jun. 28-Jul. 02, vol. 3, pp. 1484-1486.

Liu, A., C. Peng, and Y.-S. Chang, 1996. Mystery ship detected in SAR image, Eos, Transactions American Geophysical Union, 77(3): 17.

Liu, A.K. and M.-K. Hsu, 2004. Internal wave study in the South China Sea using synthetic aperture radar (SAR), International Journal of Remote Sensing, 25(7-8): 1261-1264.

Lucassen, J., 1982. Effect of surface-active material on the damping of gravity waves: A reappraisal, Journal of Colloid Interface Science, 85: 5258.

Mason, D., I. Davenport, G. Robinson, R. Flather, and B. McCartney, 1995. Construction of an intertidal digital elevation model by the "WaterLine' Method, Geophysical Research Letters, 22(23): 3187-3190.

Migliaccio, M., F. Nunziata, A. Montuori, X. Li, and W.G. Pichel, 2011. A multifrequency polarimetric SAR processing chain to observe oil fields in the Gulf of Mexico, IEEE Transactions on Geoscience and Remote 
Sensing, 49(12): 4729-4737.

Monaldo, F.M., D.R. Thompson, R.C. Beal, W.G. Pichel, and P. Clemente-Colon, 2001. Comparison of SAR-derived wind speed with model predictions and ocean buoy measurements, IEEE Transactions on Geoscience and Remote Sensing, 39(12): 2587-2600.

Ouchi, K., S. Tamaki, H. Yaguchi, and M. Iehara, 2004. Ship detection based on coherence images derived from cross correlation of multilook SAR images, IEEE Geoscience and Remote Sensing Letters, 1(3): 184-187.

Park, S.M., C.S. Yang, and Y.S. Oh, 2010. Numerical simulation of radar backscattering from oil spills on sea surface for L-band SAR, Korean Journal of Remote Sensing, 26(1): 21-27(in Korean with Engilsh abstract).

Perez-Marrodan, M., 1998. ENVISYS environmental monitoring warning and emergency management system, Proc. of the AFCEA Kiev Seminar, Kiev, Ukraine, May 28-29, pp. 122-132.

Rodenas, J.A. and R. Garello, 1997. Wavelet analysis in SAR ocean image profiles for internal wave detection and wavelength estimation, IEEE Transactions on Geoscience and Remote Sensing, 35(4): 933-945.

Shemer, L., M. Marom, and D. Markman, 1993. Estimates of currents in the nearshore ocean region using interferometric synthetic aperture radar, Journal of Geophysical Research, 98(C4): 7001-7010.

Skøelv, Å. and T. Wahl, 1993. Oil spill detection using satellite based SAR, Phase 1B competition report, Technical report, Norwegian Defence
Research Establishment, Kjeller, Norway.

Solberg, A.H.S., G. Storvik, R. Solberg, and E. Volden, 1999. Automatic detection of oil spills in ERS SAR images, IEEE Transactions on Geoscience and Remote Sensing, 37(4): 1916-1924.

Vachon, P.W., S.J. Thomas, J.A. Cranton, C. Bjerkelund, F.W. Dobson, and R.B. Olsen, 1998. Monitoring the coastal zone with the RADARSAT satellite, Oceanology International 98, Brighton, UK, Mar. 10-13, pp. 29-38.

Valenzuela, G.R., 1978. Theories for the interaction of electromagnetic and ocean waves-A review, Boundary-Layer Meteorology, 13: 61-85.

Van der Wal, D., P.M.J. Herman, and A. Wielemakervan den Dool, 2005. Characterisation of surface roughness and sediment texture of intertidal flats using ERS SAR imagery, Remote Sensing of Environment, 98(1): 96-109.

Xu, Q., H. Lin, X. Li, J. Zuo, Q. Zheng, W.G. Pichel, and Y. Liu, 2010. Assessment of an analytical model for sea surface wind speed retrieval from spaceborne SAR, International Journal of Remote Sensing, 31(4): 993-1008.

Yang, C.S., D.Y. Kim, and J.H. Oh, 2009. Study on improvement of oil spill prediction using satellite data and oil-spill model: Hebei Spirit oil spill, Korean Journal of Remote Sensing, 25(5): 435-444(in Korean with Engilsh abstract).

Zhang, B., W. Perrie, X. Li, and W.G. Pichel, 2011. Mapping sea surface oil slicks using RADARSAT-2 quad-polarization SAR image, Geophysical Research Letters, 38(L10602): doi:10.1029/2011GL047013. 